\title{
$\mathbf{C m}^{2}$-Scale Synthesis of MoTe 2 Thin Films with Large Grains and Layer Control
} David J. Hynek, Raivat M. Singhania, Shiyu Xu, Benjamin Davis, Lei Wang, Milad Yarali, Joshua V. Pondick, John M. Woods, Nicholas C. Strandwitz, and Judy J. Cha*

D. J. Hynek, S. Xu, Dr. L. Wang, Dr. M. Yarali, J. V. Pondick, Dr. J. M. Woods, Prof. J. J. Cha* Energy Sciences Institute, Department of Mechanical Engineering and Materials Science, Yale University, West Haven, CT 06516, United States

E-mail: judy.cha@yale.edu

R. M. Singhania, B. Davis, Prof. N. C. Strandwitz

Department of Materials Science and Engineering, Lehigh University, Bethlehem, PA 18015, United States

\begin{abstract}
Owing to the small energy differences between its polymorphs, $\mathrm{MoTe}_{2}$ can access a full spectrum of electronic states, from the $2 \mathrm{H}$ semiconducting state to the $1 \mathrm{~T}^{\prime}$ semimetallic state, and from the $T_{d}$ Weyl semimetallic state to the superconducting state in the $1 T^{\prime}$ and $T_{d}$ phase at low temperature. Thus, it is a model system for phase transformation studies as well as quantum phenomena such as the quantum spin Hall effect and topological superconductivity. Careful studies of $\mathrm{MoTe}_{2}$ and its potential applications require large-area $\mathrm{MoTe}_{2}$ thin films with high crystallinity and thickness control. Here, we present $\mathrm{cm}^{2}$-scale synthesis of $2 \mathrm{H}-\mathrm{MoTe}_{2}$ thin films with layer control and large grains that span several microns. Layer control is achieved by controlling the initial thickness of the precursor $\mathrm{MoO}_{\mathrm{x}}$ thin films, which are deposited on sapphire substrates by atomic layer deposition and subsequently tellurized. Despite the van der Waals epitaxy, the precursor-substrate interface is found to critically determine the uniformity in thickness and grain size of the resulting $\mathrm{MoTe}_{2}$ films: $\mathrm{MoTe}_{2}$ grown on sapphire show uniform films while $\mathrm{MoTe}_{2}$ grown on amorphous $\mathrm{SiO}_{2}$ substrates form islands. This synthesis strategy decouples the layer control from the variabilities of growth conditions for robust growth results, and is applicable to grow other transition metal dichalcogenides with layer control.
\end{abstract}


Keywords: $\mathrm{MoTe}_{2}$, thin-film synthesis, atomic layer deposition, chemical vapor deposition, phase-change material, transition-metal dichalcogenides, 2D materials

Transition metal dichalcogenides (TMDs) have been extensively studied over the last decade for their layer-dependent physical and electrochemical properties that can be used for optoelectronic, flexible, and energy-harvest and storage devices. ${ }^{1-4}$ In addition, TMDs provide a platform to explore a large electronic phase space as several structural phases can be accessed with each phase associated with a distinct electronic state. ${ }^{5}$ Tellurides, such as $\mathrm{MoTe}_{2}$ and $\mathrm{WTe}_{2}$, have demonstrated almost the entire spectrum of electronic phases, including superconductivity, ${ }^{6-8}$ quantum spin Hall state,,${ }^{910}$ Weyl semimetallic state, ${ }^{11,12}$ semimetallic state, and semiconducting state. $\mathrm{MoTe}_{2}$ in particular has shown promise for phase-change memory applications due to the small energy difference between the $2 \mathrm{H}$ and $1 \mathrm{~T}^{\prime}$ phase ${ }^{13}$ with experimental demonstrations of the phase switching induced by strain, ${ }^{14}$ gating, ${ }^{15,16}$ and heating. ${ }^{17}$ Despite the growing interests in the tellurides, large-scale synthesis of telluride thin films with precise layer control remains a challenge, although such synthesis has been demonstrated for sulfides and selenides. ${ }^{18-21}$

For transport studies, mechanical exfoliation can yield clean $\mathrm{MoTe}_{2}$ flakes from bulk crystals. ${ }^{3}$ However, mechanical exfoliation does not provide control over the thickness, size, or shape of the flakes and the yield is low. Recent synthesis efforts have shown $\mathrm{MoTe}_{2}$ monolayer flakes that are a few microns large. ${ }^{22,23}$ Large-area thin films of $\mathrm{MoTe}_{2}$ have been demonstrated using molecular beam epitaxy, ${ }^{24}$ chemical vapor deposition, ${ }^{13,25-28}$ and solution phase synthesis, ${ }^{29}$ albeit for a limited range of thicknesses. Robust growth results of $\mathrm{MoTe}_{2}$ thin films from monolayer to any arbitrary thickness with large grains have yet to be demonstrated. In this 
work, we convert $\mathrm{MoO}_{\mathrm{x}}(2<\mathrm{x}<3)$ thin films deposited on c-plane sapphire (0001) substrates by atomic layer deposition (ALD) to achieve $\mathrm{cm}^{2}$-scale synthesis of $\mathrm{MoTe}_{2}$ films with thickness down to a monolayer and large grains. The use of ALD precursor films enables thickness control and scalable growth, and decouples the thickness control from variations in growth conditions, leading to reproducible and robust growth results. The low reactivity of Te is overcome by the generation of the chemical intermediate hydrogen telluride, which readily coverts $\mathrm{MoO}_{\mathrm{x}}$ to $\mathrm{MoTe}_{2}$. We observe a direct correlation between the number of ALD cycles of the $\mathrm{MoO}_{\mathrm{x}}$ films and the number of layers in the resulting $\mathrm{MoTe}_{2}$ films, ranging from 8 layers down to a monolayer. Large grains of $2 \mathrm{H}-\mathrm{MoTe}_{2}$ are achieved based on nucleation-limited growth of the $2 \mathrm{H}$ phase out of an initial $1 \mathrm{~T}^{\prime}-\mathrm{MoTe}_{2}$ film with continual supply of tellurium, as previously reported. ${ }^{13,30}$

\section{Results and Discussion}

Amorphous $\mathrm{MoO}_{\mathrm{x}}$ thin films were deposited on sapphire substrates by ALD with cycle numbers ranging from 5 to 135 cycles (Methods). $\mathrm{MoO}_{\mathrm{x}}$ films were chosen as the precursor to $\mathrm{MoTe}_{2}$ over Mo to minimize strain during conversion, as volume expansion from $\mathrm{MoO}_{3}$ to $\mathrm{MoTe}_{2}$ is $\sim 8$ times smaller than that from Mo to MoTe $2 .{ }^{30,31}$ Low-energy ion scattering spectroscopy (LEIS) was performed on the $\mathrm{MoO}_{\mathrm{x}}$ films to determine the surface coverage of $\mathrm{MoO}_{\mathrm{x}}$ on sapphire. At 5 ALD cycles, $\mathrm{MoO}_{\mathrm{x}}$ mostly covers the substrate; at 14 cycles, the coverage is complete and no $\mathrm{Al}$ peaks from the sapphire substrate are observed in the LEIS data (Figure S1, Supporting Information). 
The oxide films were placed in a two-zone tube furnace and heated to $580{ }^{\circ} \mathrm{C}$ while Te source powder was placed upstream and heated to $570{ }^{\circ} \mathrm{C}$ in the presence of $\mathrm{H}_{2}$ gas at atmospheric pressure (Figure 1a). The vaporized Te reacts with $\mathrm{H}_{2}$ to form $\mathrm{H}_{2} \mathrm{Te}$, which converts $\mathrm{MoO}_{\mathrm{x}}$ to $\mathrm{MoTe}_{2}$ (Methods). ${ }^{32}$ Figure $1 \mathrm{~b}$ and $1 \mathrm{c}$ show the cross-section transmission electron microscope (TEM) images of a 14-cycle $\mathrm{MoO}_{\mathrm{x}}$ film and the converted bilayer $\mathrm{MoTe}_{2}$ film on a sapphire substrate, prepared by focused ion beam milling (Methods). The synthesized $\mathrm{MoTe}_{2}$ films are in the $2 \mathrm{H}$ phase, as characterized by plan-view TEM (Figure 1d-g). While the bright-field TEM image shows interesting contrast variations (Figure 1d), the selected-area electron diffraction from the same region shows presence of two grains (Figure 1d inset). Dark-field (DF) TEM images formed from the two diffraction spots (Figure 1e, f) reveal a clear boundary between the two grains. The contrast variations are thus most likely due to crumpling of the film caused by the transfer process and are not indicative of the film quality. Much weaker diffraction spots are observed in between the two sets of diffraction spots, suggesting potentially a third grain in the field of view of $4 \mathrm{\mu m}^{2}$ of $\mathrm{MoTe}_{2}$. Figure S2 provides a complete DF-TEM mapping of the grain shown in Figure 1f, which is $\sim 10 \mu m$ wide. We note that for plan-view TEM, MoTe $\mathrm{F}_{2}$ films were grown on $\mathrm{SiO}_{2}$ substrates for easy lift-off using hydrofluoric acid as etching of sapphire for lift-off was proven difficult. Figure 1h shows optical images of $\mathrm{MoO}_{\mathrm{x}}$ and $\mathrm{MoTe}_{2}$ films of varying thicknesses on sapphire before and after tellurization, which demonstrates successful fabrication of $\mathrm{cm}^{2}$-scale $\mathrm{MoTe}_{2}$ films on sapphire. 
a)

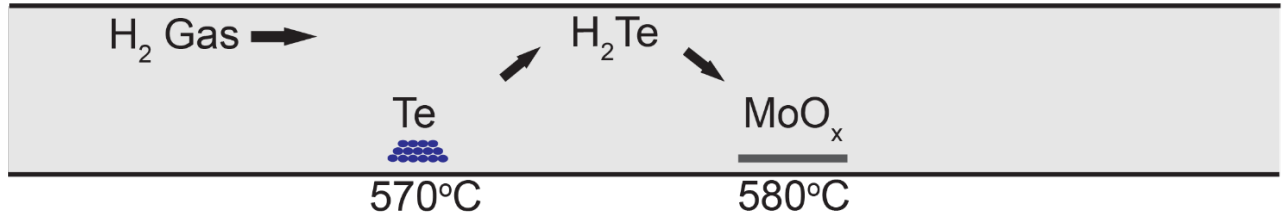

b)

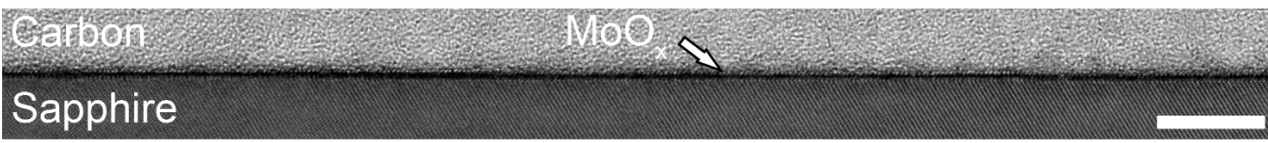

c)

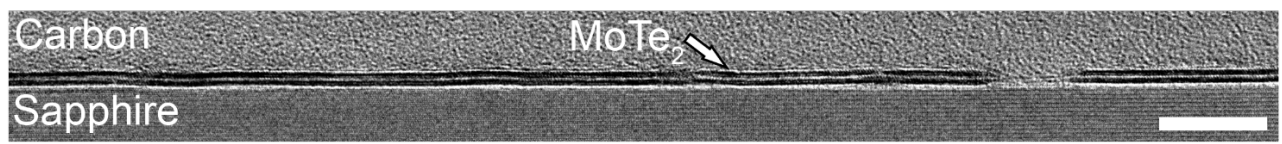

d)

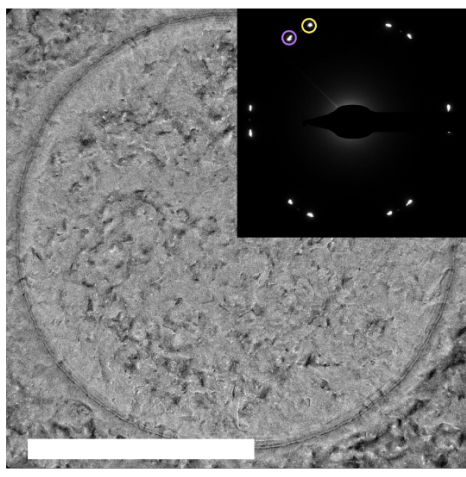

e)
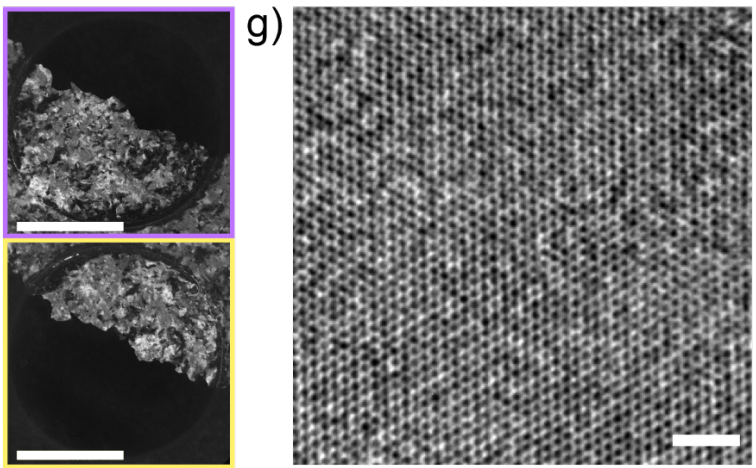

h)

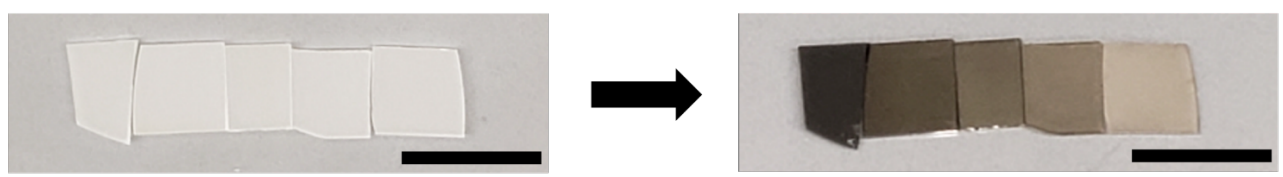

Figure 1: Growth overview of $\mathrm{MoTe}_{2}$ thin films. a) Two-zone furnace growth schematic. b, c)

TEM cross-section images of a 14-cycle $\mathrm{MoO}_{\mathrm{x}}$ film (b) and converted $\mathrm{MoTe}_{2}$ film (c) on sapphire substrates. Scale bars, $10 \mathrm{~nm}$. d) TEM image of a $2 \mathrm{H} \mathrm{MoTe} 2$ film grown on $\mathrm{SiO}_{2}$, synthesized at $580{ }^{\circ} \mathrm{C}$ for 3 hours. Inset: The selected area electron diffraction pattern shows only two grains in field of view. Scale bar, $1 \mu \mathrm{m}$. e, f) Dark-field TEM images of the two grains present in (d), obtained from selecting the diffraction spot circled in purple (e) and yellow (f), respectively. Scale bar, $1 \mu \mathrm{m}$. g) High-resolution TEM image of the $\mathrm{MoTe}_{2}$ film shows the expected hexagonal lattice of the $2 \mathrm{H}$ phase. Scale bar, $2 \mathrm{~nm}$. h) Optical images of (left) $\mathrm{MoO}_{\mathrm{x}}$ thin films deposited on sapphire; from left to right corresponds to 135, 60, 27, 14, and 5 ALD cycles, and (right) the corresponding $\mathrm{MoTe}_{2}$ films after tellurization. Scale bar, $1 \mathrm{~cm}$. 
Figure 2 shows cross-section TEM images of $\mathrm{MoTe}_{2}$ films of varying thickness: monolayer (Figure 2a), bilayer (Figure 2b), 2-3 layers (Figure 2c), 3-4 layers (Figure 2d), and 7-8 layers (Figure 2e). The converted $\mathrm{MoTe}_{2}$ films are uniform in their thickness within a single layer step, demonstrating a high degree of uniformity across the substrate. Thus, the conversion from $\mathrm{MoO}_{\mathrm{x}}$ to $\mathrm{MoTe}_{2}$ must be layer-by-layer and the number of layers of $\mathrm{MoTe}_{2}$ can be controlled by the ALD cycle numbers of $\mathrm{MoO}_{\mathrm{x}}$. For the films shown in Figure 2, the corresponding ALD cycle numbers of the initial $\mathrm{MoO}_{\mathrm{x}}$ films are 5, 14, 27, 60, and 135 where a full surface coverage of the oxide film on sapphire occurs between 5 and 14 cycles (Figure S1, Supporting Information). There is a good correlation between ALD cycle number and $\mathrm{MoTe}_{2}$ film thickness: the number of $\mathrm{MoTe}_{2}$ layers increases monotonically with the number of ALD cycles (Figure S3, Supporting Information).

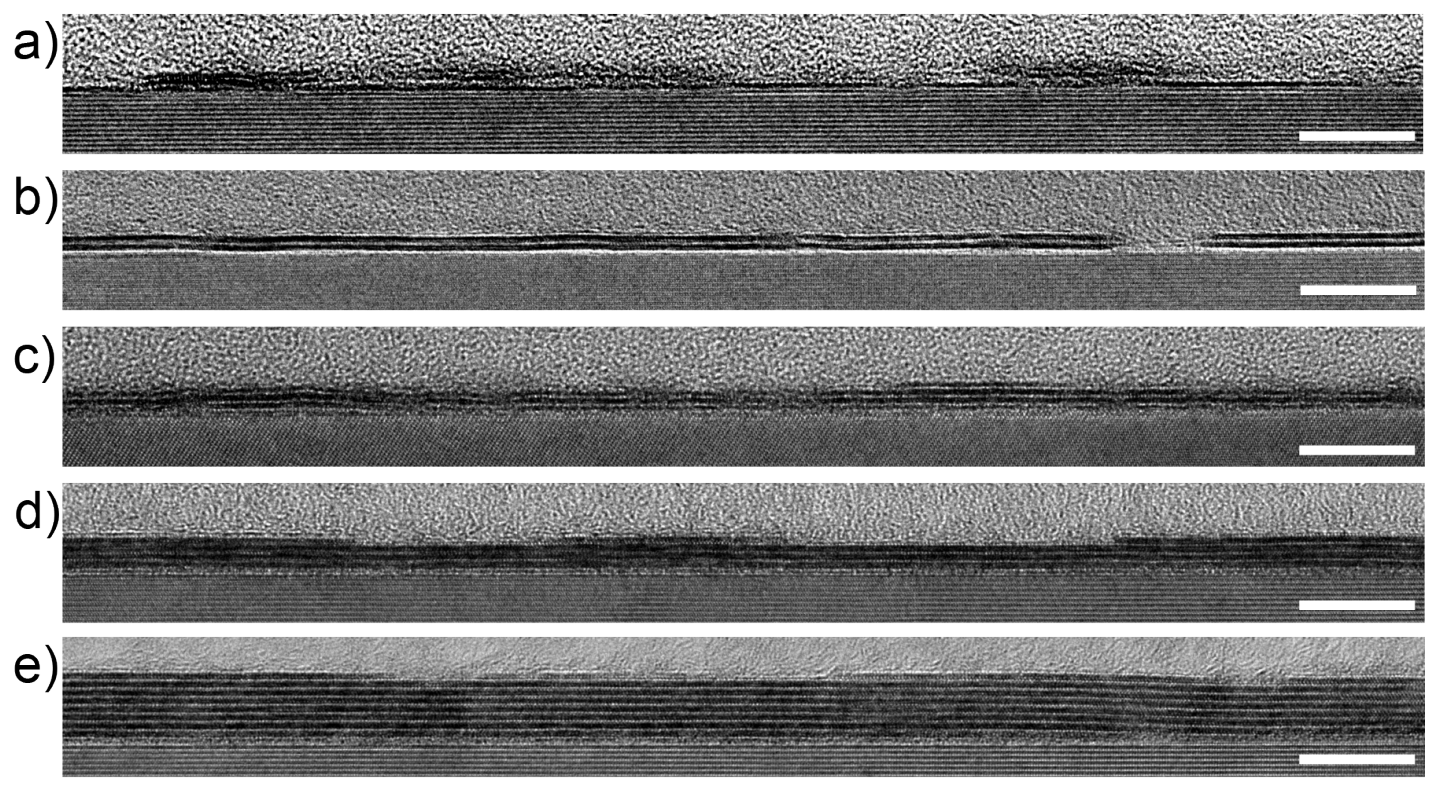

Figure 2: Cross-sections of $2 \mathrm{H}$ MoTe 2 films on sapphire. Cross-section TEM images of monolayer (a), bi-layer (b), 2-3 layer (c), 3-4 layer (d), and 7-8 layer (e) $\mathrm{MoTe}_{2}$ thin films converted from 5, 14, 27, 60, and 135 cycle $\mathrm{MoO}_{\mathrm{x}}$ films deposited on sapphire, respectively. Scale bars, $10 \mathrm{~nm}$. 
The $2 \mathrm{H}$ phase of the $\mathrm{MoTe}_{2}$ films was confirmed by Raman spectroscopy (Figure 3a). In

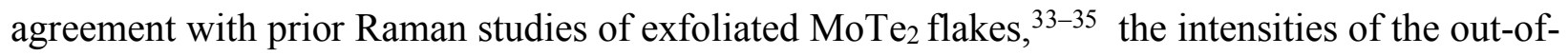
plane $A_{1,}\left(170 \mathrm{~cm}^{-1}\right)$ and bulk-inactive $B_{2 g}^{1}\left(290 \mathrm{~cm}^{-1}\right)$ Raman modes are sensitive to layer number (Figure S4, Supporting Information), with the $A_{1, a}$ peak becoming dominant over the inplane $E_{2 g}^{1}\left(234 \mathrm{~cm}^{-1}\right)$ peak in monolayer. The $\mathrm{MoTe}_{2}$ film converted from the 5 cycle $\mathrm{MoO}_{\mathrm{x}}$ film shows a dominant $A_{1 g}$ peak, verifying that the film is monolayer in agreement with the crosssection TEM result (Figure 2a). Because the $A_{1, g}$ and $B_{2 g}^{1}$ modes are sensitive to layer number, we examined the $A_{1 g}$ and $B_{2 g}^{1}$ modes at various locations of the films across a $5-10 \mathrm{~mm}$ region, which confirmed thickness uniformity at wafer scale (Figure S5, Supporting Information). Chemical analysis of the converted films using X-ray photoelectron spectroscopy shows a full conversion to $\mathrm{MoTe}_{2}$ as evidenced by the peak shift of the Mo $3 \mathrm{~d}$ peaks from $\mathrm{MoO}_{\mathrm{x}}$ to $\mathrm{MoTe}_{2}$ (Figure 3b). ${ }^{28}$ Energy dispersive x-ray spectroscopy shows that the stoichiometry of our $\mathrm{MoTe}_{2}$ films is identical to that of a flake exfoliated from bulk $\mathrm{MoTe}_{2}$ grown by chemical vapor transport (Figure 3c, Methods).

Surface uniformity of the films was further characterized by atomic force microscopy (AFM) (Figure 4; additional data in Figure S6, Supporting Information). For the monolayer MoTe 2 (Figure 4a), the AFM image shows patchy monolayer coverage across the substrate. This is attributed to insufficient precursor from the 5 ALD cycle $\mathrm{MoO}_{\mathrm{x}}$ film to yield a complete monolayer $\mathrm{MoTe}_{2}$ film. The AFM observation agrees with the cross-section TEM image of the monolayer case (Figure 2a). The $\mathrm{MoTe}_{2}$ converted from the 14-cycle $\mathrm{MoO}_{\mathrm{x}}$ shows a mostly uniform $\mathrm{MoTe}_{2}$ film with pinholes of $\sim 2 \mathrm{~nm}$ in depth (Figure 4b), which indicates that the film is bilayer, in agreement with the cross-section TEM result (Figure 2b). The presence of pinholes 

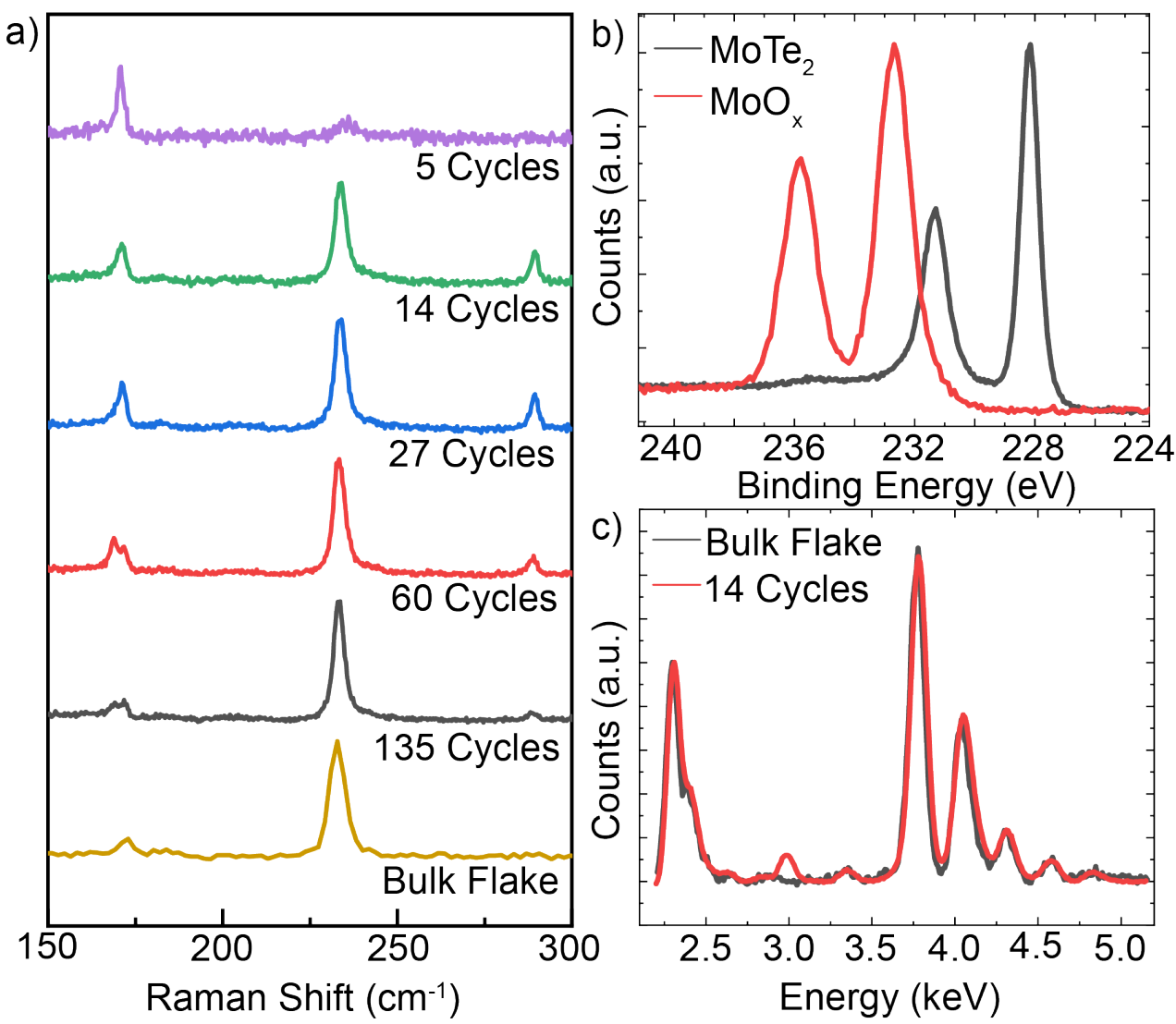

Figure 3: Spectroscopic data from 2H MoTe 2 films. a) Raman spectra of $2 \mathrm{H} \mathrm{MoTe}_{2}$ on sapphire using a $633 \mathrm{~nm}$ laser. Different cycle numbers correspond to different initial oxide thicknesses. The $\mathrm{MoTe}_{2}$ film converted from the 5 cycle $\mathrm{MoO}_{\mathrm{x}}$ is monolayer based on the higher intensity of the $A_{1, g}$ mode $\left(170 \mathrm{~cm}^{-1}\right)$ compared to the $E_{2 g}^{1}$ mode $\left(234 \mathrm{~cm}^{-1}\right)$. b) X-ray photoelectron spectroscopy showing Mo $3 d$ peaks from $\mathrm{MoO}_{\mathrm{x}}$ films on sapphire before (red) and after (black) tellurization. The observed chemical shift indicates a full conversion from the oxide to the telluride. c) Normalized energy dispersive x-ray spectroscopy data of a $\mathrm{MoTe}_{2}$ film converted from a 14 cycle $\mathrm{MoO}_{\mathrm{x}}$ thin film (red), overlaid with a reference spectrum of a bulk flake (black), showing that the stoichiometry for the converted film is identical to bulk crystal $\mathrm{MoTe}_{2}$. 
suggests that $14 \mathrm{ALD}$ cycles of $\mathrm{MoO}_{\mathrm{x}}$ is close to the optimal cycle number for a complete bilayer film, but falls just short. For larger-cycle $\mathrm{MoO}_{\mathrm{x}}$ films (> 27 cycles) (Figure 4c, d), converted $\mathrm{MoTe}_{2}$ films are uniform with no visible pinholes on the surface, and the height of the islands indicates one layer. These step heights are consistent with variations seen in cross-section TEM images (Figure 2c, d), and are uniformly present throughout the substrate (Figure S6, Supporting Information). Based on the AFM topographic images, 27 and 60 cycle $\mathrm{MoO}_{\mathrm{x}}$ films yielded $40 \%$ areal coverage of the topmost layer in both cases, resulting in $\sim 2.4$ and 3.4-layer thick $\mathrm{MoTe}_{2}$ films, respectively.

a)

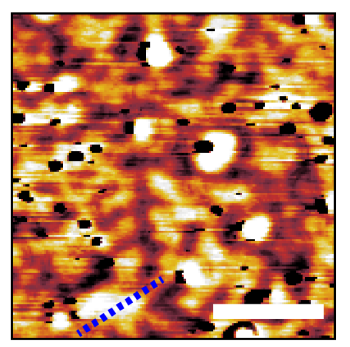

b)

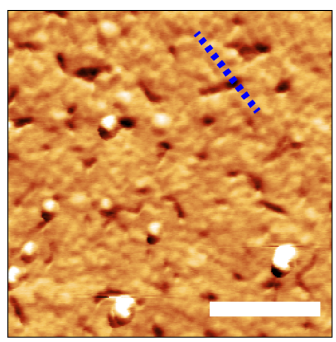

c)

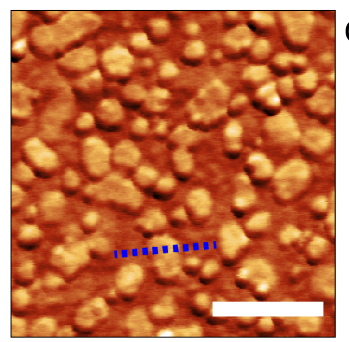

d)

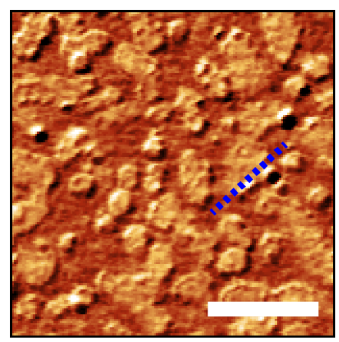

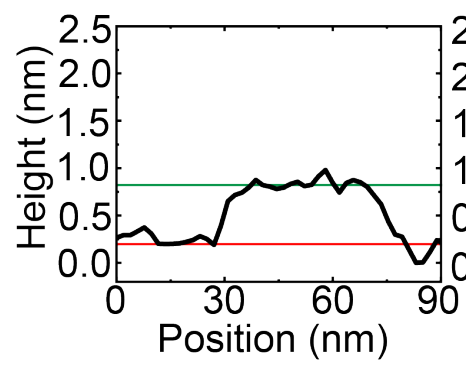

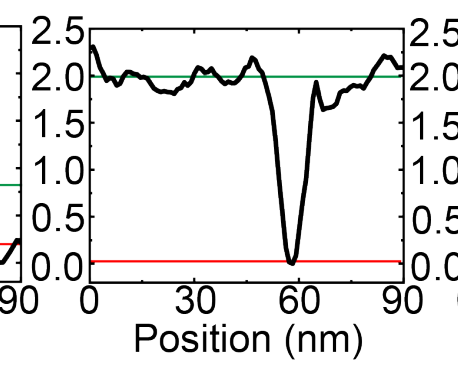

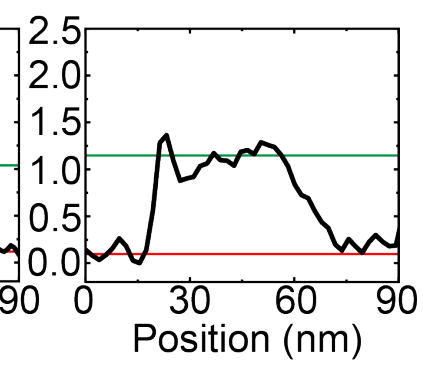

Figure 4: Atomic force microscopy of $\mathrm{MoTe}_{2}$ thin films. AFM images and corresponding height profiles of $\mathrm{MoTe}_{2}$ thin films converted from a) 5 cycle, b) 14 cycle, c) 27 cycle, and d) 60 cycle $\mathrm{MoO}_{\mathrm{x}}$ films. Scale bars, $100 \mathrm{~nm}$. The height profiles were taken from the blue dotted lines marked in the AFM images. They show islands with $\sim 1 \mathrm{~nm}$ step height, which corresponds to the thickness of one layer of $\mathrm{MoTe}_{2}$. For the $\mathrm{MoTe}_{2}$ shown in $\mathbf{b}, \sim 2 \mathrm{~nm}$-deep pits are observed rather than islands, which correspond to pinholes in the bilayer $\mathrm{MoTe}_{2}$. 
Such analysis allows us to estimate the ideal ALD cycle number that will yield a $\mathrm{MoTe}_{2}$ film with no variations in thickness across an entire substrate. For example, based on fits for lowcycle films, we estimate that 46 cycle $\mathrm{MoO}_{\mathrm{x}}$ would yield a complete tri-layer $\mathrm{MoTe}_{2}$ film (Figure S3, Supporting Information).

The synthesized 2H-MoTe 2 films show large grains due to the nucleation-limited synthesis of the $2 \mathrm{H}$ phase. ${ }^{13}$ In the early stage of the tellurization, $\mathrm{MoTe}_{2}$ films are in the $1 \mathrm{~T}^{\prime}$ phase. Figure 5a and $5 \mathrm{~b}$ show TEM images of a $\mathrm{MoTe}_{2}$ film that was tellurized for $1 \mathrm{hr}$ instead of $4 \mathrm{hrs}$. A clear boundary is observed between $2 \mathrm{H}$ and $1 \mathrm{~T}^{\prime}$ areas. The selected area diffraction pattern (Figure $5 \mathrm{c}$ ) shows the presence of a single-crystalline $2 \mathrm{H}$ grain and poly-crystalline $1 \mathrm{~T}^{\prime}$ regions with small nanoscale grains as evidenced by the ring diffraction patterns (high-resolution TEM image of 1T' phase in Figure S7, Supporting Information). Using Raman spectroscopy, we followed the conversion progression of the $\mathrm{MoTe}_{2}$ films. We observe that $\mathrm{MoTe}_{2}$ is initially in the $1 \mathrm{~T}^{\prime}$ phase, then $2 \mathrm{H}$ grains nucleate out of the $1 \mathrm{~T}^{\prime}$ phase and grow. This is tracked optically as the $2 \mathrm{H}$ phase appears lighter relative to the $1 \mathrm{~T}^{\prime}$ phase. By changing the reaction temperature and thus controlling the nucleation and growth rate of $2 \mathrm{H}$ grains, the $2 \mathrm{H}$ grain size ranged from $20 \mathrm{um}$ (Figure S2, Supporting Information) to $1 \mathrm{~mm}$ (Figure 5d). With longer reaction time, the $2 \mathrm{H}$ grains continue to grow and eventually merge, resulting in a complete $2 \mathrm{H} \mathrm{MoTe}_{2}$. A schematic of the phase conversion is shown in Figure 5g. The nucleation-limited synthesis enables synthesis of large-grain $2 \mathrm{H}-\mathrm{MoTe}_{2}$ thin films. Our results agree with previous studies that show the same synthesis pathway, ${ }^{13}$ which suggests the initial $1 \mathrm{~T}^{\prime}$ phase is due to tellurium deficiency at the beginning of tellurization when Te begins to replace oxygen in $\mathrm{MoO}_{\mathrm{x}}$. With sufficient time for tellurization, a continual supply of Te leads to the nucleation of the $2 \mathrm{H}$ phase. 
a)

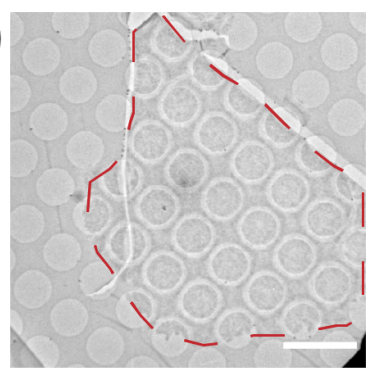

b)

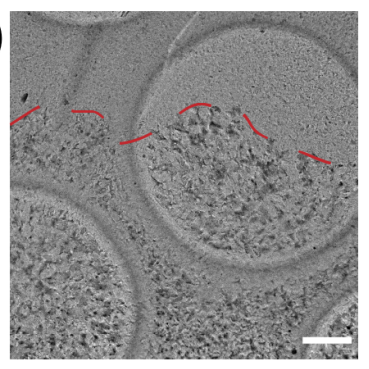

d)

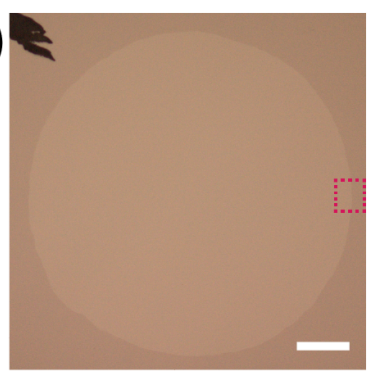

$1 \mathrm{~T}^{\prime}$

g)

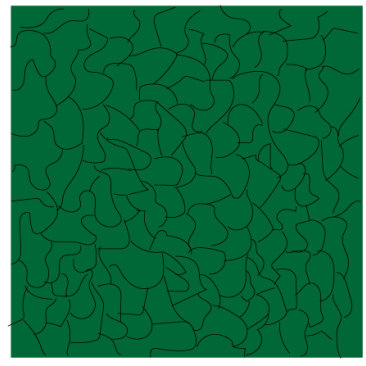

e)

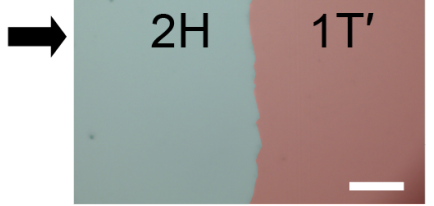

$2 \mathrm{H} / 1 \mathrm{~T}^{\prime}$

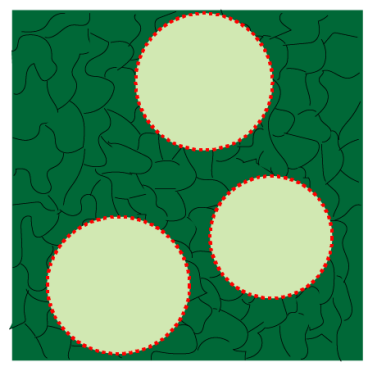

Growth Time c)

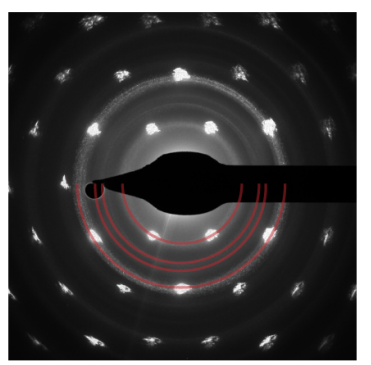

f)

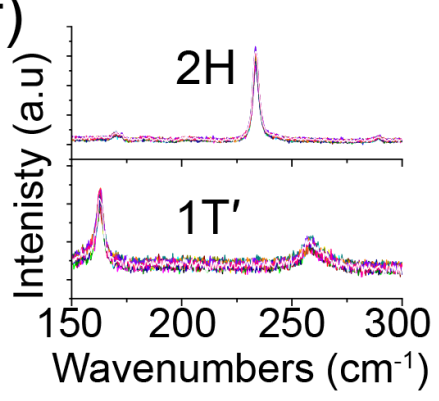

$2 \mathrm{H}$

Figure 5: Phase transition-mediated synthesis of 2H MoTe2. a) TEM image shows a large 2H grain in the center of an otherwise $1 \mathrm{~T}^{\prime}$ film. Scale bar, $5 \mu \mathrm{m}$. b) Higher-magnification TEM image of the boundary shows the border of the $2 \mathrm{H}$ grain and the $1 \mathrm{~T}^{\prime}$ region clearly. Scale bar, $500 \mathrm{~nm}$. c) Selected area electron diffraction taken from region (b) shows one set of diffraction spots for the $2 \mathrm{H}$ grain, and diffraction rings for the $1 \mathrm{~T}^{\prime}$ region, suggesting nanoscale grains. The diffraction rings overlaid with the dotted half circles are, from the inner to outer circles, the (200), (210), (310) and (020) planes of the $1 \mathrm{~T}^{\prime} \mathrm{MoTe}_{2}$ on zone-axis, respectively. d) Optical image of 7-8 layer MoTe $\mathrm{M}_{2}$ synthesized at $600{ }^{\circ} \mathrm{C}$ for 4 hours, tracking a single $2 \mathrm{H}$ grain of size $>$ 
$1 \mathrm{~mm}$. Scale bar, $200 \mu \mathrm{m}$. e) Raman map of border of $2 \mathrm{H}$ grain and initial 1T' film. Scale bar, 5 $\mu \mathrm{m}$. f) Overlaid spectra from regions shown in (e). 16 spectra shown for each phase. g) Nucleation and growth of the $2 \mathrm{H}$ phase out of the initial $1 \mathrm{~T}^{\prime}$ phase. As long as the Te vapor pressure is maintained, full conversion of $1 \mathrm{~T}^{\prime}$ to $2 \mathrm{H}$ occurs in the range of 2-4 hours of reaction time at $580{ }^{\circ} \mathrm{C}$ and $6-8$ hours at $600{ }^{\circ} \mathrm{C}$.

To characterize the film quality, 4-probe devices were fabricated from 3-4 and 7-8 layer thick $\mathrm{MoTe}_{2}$ films using $\mathrm{Cr} / \mathrm{Au}$ contacts (Methods). Figure 6a shows the resistance of the as-grown 78 layer film as temperature was decreased, and Figure $6 \mathrm{~b}$ shows the $\log$ of conductivity as a function of inverse temperature for three samples, which show semiconducting behavior as expected. Using the Arrhenius equation $\sigma=\sigma_{0} e^{\frac{-E_{A}}{K_{b} T}}$ where $\sigma$ is conductivity, $\sigma_{0}$ is a temperature independent scaling factor, $E_{A}$ is the activation energy, and $K_{b}$ is Boltzmanns constant, an activation energy of $0.14 \mathrm{eV}$ was extracted for the as-grown 7-8 layer thick $\mathrm{MoTe}_{2}$. This value is much less than the optical bandgap of $1.1 \mathrm{eV},{ }^{36}$ but it is similar to the reported activation energies of $\mathrm{MoTe}_{2}$ flakes exfoliated from bulk, ${ }^{17}$ which is attributed to differences in work functions between the contact metal and the film. Thus, transport data suggests that the Fermi energy of our $\mathrm{MoTe}_{2}$ films converted from $\mathrm{MoO}_{\mathrm{x}}$ films on sapphire must be similar to bulk-exfoliated $\mathrm{MoTe}_{2}$ flakes. Etching the films with Ar (Methods) resulted in a factor of 4 reduction in the activation barrier: $0.07 \mathrm{eV}$ for the 3-4 layer film and $0.03 \mathrm{eV}$ for the 7-8 layer film. This is attributed to the creation of Te vacancies induced by etching, which have been shown to decrease the Schottky barrier in $\mathrm{MoTe}_{2}$ flakes exfoliated from bulk. ${ }^{37}$ Comparison of Raman spectra before and after Ar etching shows clearly that the $\mathrm{MoTe}_{2}$ film is degraded after etching (Figure S8, Supporting Information). 

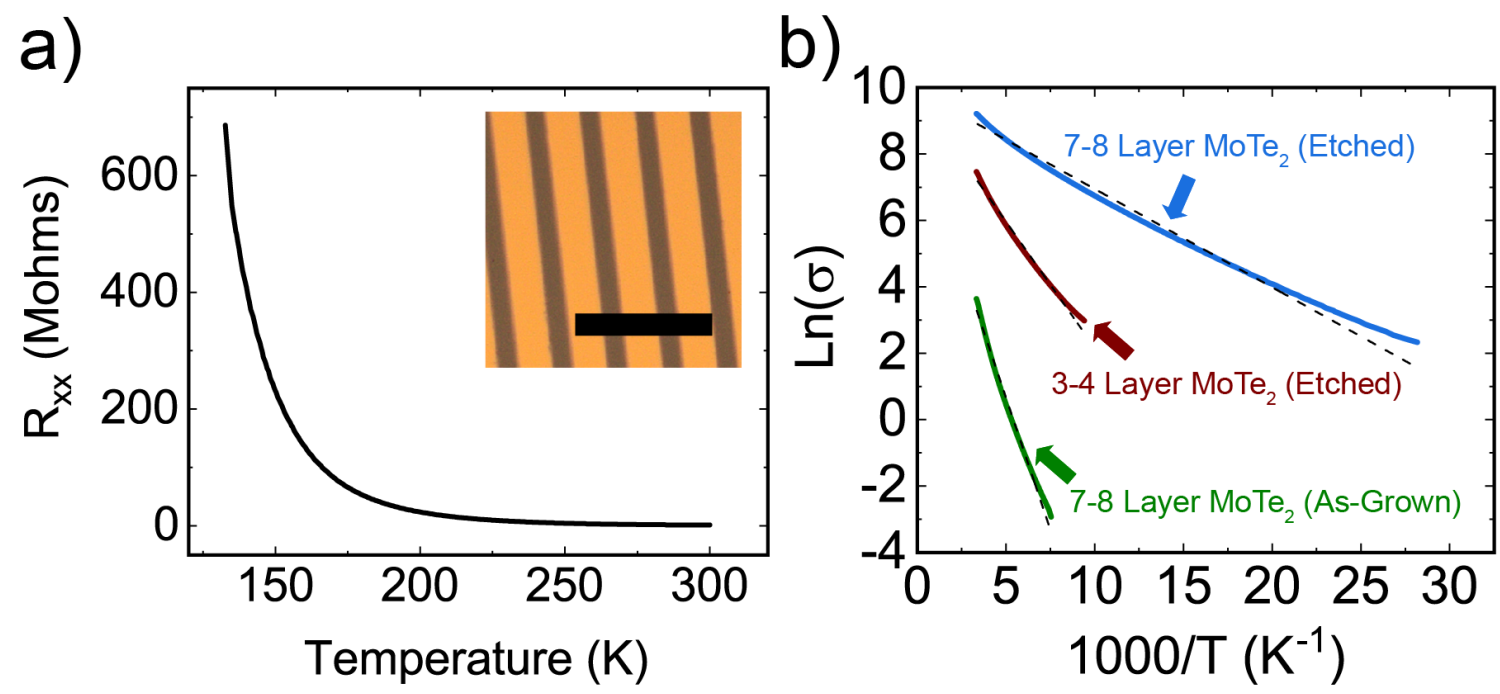

Figure 6: Temperature-dependent resistance of $\mathrm{MoTe}_{2}$ thin films. a) Resistance vs. temperature curve for a 7-8 layer thick as-grown $\mathrm{MoTe}_{2}$ device down to $78 \mathrm{~K}$. Inset) Optical image of the device. Scale bar, $200 \mu \mathrm{m}$. b) Natural log of conductivity $(\ln (\sigma))$ vs. 1000/T, used to extract the activation energy. The green curve denotes data for the 7-8 layer thick as-grown $\mathrm{MoTe}_{2}$ device, and the blue and red curves represent 7-8 and 3-4 layer thick MoTe $\mathrm{Mevices}_{2}$ after Ar etching. Dotted lines are fits to extract the activation energy.

The choice of sapphire substrate was important to achieve large-area, uniform $2 \mathrm{H}-\mathrm{MoTe}_{2}$ thin films with large grains. When the synthesis was repeated using amorphous $\mathrm{SiO}_{2}$ substrates, $\mathrm{MoTe}_{2}$ formed islands instead of continuous films for $\mathrm{MoO}_{\mathrm{x}}$ films below 135 cycles (Figure S9, Supporting Information) even though the coverage of $\mathrm{MoO}_{\mathrm{x}}$ on sapphire and $\mathrm{SiO}_{2}$ was similar based on LEIS data (Figure S1, Supporting Information). Thus, despite the van der Waals epitaxy which is considered to have weak interactions between the substrate and the 2D film, we note a clear difference in the quality of the resulting $\mathrm{MoTe}_{2}$ film. Our observations are in agreement with previous reports that demonstrate the effect of substrate choice on the subsequent 
quality of 2D thin films. ${ }^{38,39}$ For example, c-plane sapphire or graphene substrates have yielded an epitaxial growth of $\mathrm{WSe}_{2}$ and $\mathrm{NbS}_{2}$ respectively. ${ }^{40,41}$ A possible explanation is the difference in adsorption energies of $\mathrm{MoTe}_{2}$ on sapphire and $\mathrm{SiO}_{2}$, which would promote lateral growth of continuous $\mathrm{MoTe}_{2}$ films on sapphire and dewetting of $\mathrm{MoTe}_{2}$ on $\mathrm{SiO}_{2}$. Similar observations have been made for the $\mathrm{ALD}$ growth of $\mathrm{WS}_{2}$ and diffusivity of $\mathrm{MoO}_{3}$ on amorphous $\mathrm{Al}_{2} \mathrm{O}_{3}$ versus $\mathrm{SiO}_{2}$ substrates. ${ }^{42,43}$

\section{Conclusion}

In summary, we have demonstrated a large-area, layer-controlled synthesis of $2 \mathrm{H}-\mathrm{MoTe}_{2}$ by tellurizing $\mathrm{MoO}_{\mathrm{x}}$ precursor films deposited on sapphire by ALD. We show a monotonic relation between the ALD cycle number of $\mathrm{MoO}_{\mathrm{x}}$ and the final thickness of $\mathrm{MoTe}_{2}$, which suggests that $\mathrm{MoTe}_{2}$ films with integer layer thickness can be obtained using $\mathrm{MoO}_{\mathrm{x}}$ films of ideal ALD cycle numbers. The synthesis is applicable to other TMDs, including $\mathrm{WTe}_{2}$ (Figure S10, Supporting Information). Our $\mathrm{MoTe}_{2}$ films with layer control enable further opportunities for investigations of layer-dependent properties and phase transitions of $\mathrm{MoTe}_{2}$ and related applications. For example, $\mathrm{MoTe}_{2}$ as phase change memory based on its semiconducting $2 \mathrm{H}-$ semimetallic $1 \mathrm{~T}^{\prime}$ phase conversion can be studied as a function of the layer number and substrate effects. 


\section{Methods}

Atomic Layer Deposition of $\mathrm{MoO}_{x}$ Films:

Silicon thermal oxide substrates were prepared using a standard RCA process. Samples were immersed in a 5:1:1 volume ratio solution of $\mathrm{H}_{2} \mathrm{O}(18.2 \mathrm{M} \Omega): \mathrm{NH}_{4} \mathrm{OH}: \mathrm{H}_{2} \mathrm{O}_{2}$ and subsequently immersed in a 6:1:1 solution of $\mathrm{H}_{2} \mathrm{O}: \mathrm{HCl}: \mathrm{H}_{2} \mathrm{O}_{2}$. Both rinses were conducted for 10 min between 70 and $80{ }^{\circ} \mathrm{C}$ and were immediately followed by an $\mathrm{H}_{2} \mathrm{O}$ rinse.

Sapphire substrates were cleaned in a modified version of the RCA process. ${ }^{44}$ The first step was a soak in an ethanol bath for 12 hours at room temperature, followed by a rinse with $\mathrm{H}_{2} \mathrm{O}$. Samples were then sonicated for $30 \mathrm{~min}$ at room temperature in a 1:20:79 solution of detergent:ethanol: $\mathrm{H}_{2} \mathrm{O}$. Samples were then soaked in a $3: 1 \mathrm{H}_{2} \mathrm{SO}_{4}: \mathrm{H}_{2} \mathrm{O}_{2}$ piranha solution. Finally, samples were immersed in more concentrated variants of the standard RCA solutions, comprising 2:1:1 $\mathrm{H}_{2} \mathrm{O}: \mathrm{NH}_{4} \mathrm{OH}: \mathrm{H}_{2} \mathrm{O}_{2}$ and 2:1:1 $\mathrm{H}_{2} \mathrm{O}: \mathrm{HCl}: \mathrm{H}_{2} \mathrm{O}_{2}$. Each of the latter 3 rinses was conducted for 20 min at $80{ }^{\circ} \mathrm{C}$ and was followed with an $\mathrm{H}_{2} \mathrm{O}$ rinse. All samples were dried with high purity nitrogen gas between each step.

Atomic layer deposition of $\mathrm{MoO}_{\mathrm{x}}$ films was performed in a Cambridge Nanotech S-100 reactor at a substrate temperature of $200^{\circ} \mathrm{C}$. Bis(tert-butylimido)bis(dimethylamido)molybdenum $(\mathrm{NtBu})_{2}\left(\mathrm{NMe}_{2}\right)_{2} \mathrm{Mo}$ and ozone were utilized as precursors in accordance with a previously published procedure. ${ }^{45}$ Films of different thicknesses were synthesized using cycle numbers of 5, $14,27,60$, and 135 . 


\section{Conversion of $\mathrm{MoO}_{x}$ to $\mathrm{MoTe}_{2}$ Films:}

$\mathrm{MoTe}_{2}$ thin films were synthesized through the annealing of $\mathrm{MoO}_{\mathrm{x}}$ thin films of various thicknesses grown by ALD in a tellurium atmosphere. Te powder (2 g, Sigma-Aldrich, 99.999\%) was placed in a 2-inch quartz tube at zone 1 of a two-zone furnace (MTI OTF-1200X-II), while $\mathrm{MoO}_{\mathrm{x}}$ thin films on sapphire substrates were placed downstream in the second zone of the tube furnace. After purging the tube many times with house vacuum to ensure no residual oxygen was present, the two zones were heated to $570{ }^{\circ} \mathrm{C}$ for Te powder and $580{ }^{\circ} \mathrm{C}$ (small $2 \mathrm{H}$ grains) or $600{ }^{\circ} \mathrm{C}$ (large $2 \mathrm{H}$ grains) for $\mathrm{MoO}_{\mathrm{x}}$ films in $15 \mathrm{~min}$ and held there at times ranging from $1-4 \mathrm{hrs}$ depending on the desired ratio of the $2 \mathrm{H} / 1 \mathrm{~T}^{\prime}$ phase. $\mathrm{H}_{2}$ was flowed at $100 \mathrm{sccm}$ at atmospheric pressure during the reaction. After the synthesis was completed, the chamber was purged with $200 \mathrm{sccm}$ Ar gas for 25 minutes, and then rapidly cooled to room temperature by opening the furnace cover.

\section{Surface Characterization Using LEIS:}

Analysis of the coverage of the $\mathrm{MoO}_{\mathrm{x}}$ precursor films was conducted on an ionTOF Qtac highsensitivity, low-energy ion scattering system. Samples were first subjected to a 15 min cleaning in atomic oxygen in situ, and then analyzed using a $\mathrm{He}^{+}$beam with an energy of $3 \mathrm{keV}$ and a total dose during probing of $1.1 \times 10^{14}$ ions $\cdot \mathrm{cm}^{-2}$. After surface scans, the surface was sputtered with an $\mathrm{Ar}^{+}$beam with an energy of $500 \mathrm{eV}$ and a dose of $1 \times 10^{15}$ ions $^{\cdot} \mathrm{cm}^{-2}$, which was expected to remove approximately one monolayer. 
Structural and Chemical Characterization:

Plan-view and cross-section TEM images were taken using a FEI Titan Themis transmission electron microscope with an image corrector at the Advanced Science Research Center at the City University of New York. To avoid sample damage, most TEM images were taken at $80 \mathrm{kV}$ except for Figure 2b, which was taken at $200 \mathrm{kV}$. For cross-section imaging, a Helios G4 UX DualBeam FIB/SEM from FEI was used to extract lamellas from samples on both $\mathrm{SiO}_{2}$ and sapphire substrates. To protect the samples, a thin $(\sim 1 \mu \mathrm{m})$ layer of carbon was deposited on the films using an ink pen (Sharpie Brand) and was allowed to dry for $\sim 3$ hours under a nitrogen atmosphere. To prevent charging on samples grown on sapphire during FIB milling, a $100 \mathrm{~nm}$ layer of gold was deposited using a Leica sputter coater. Inside a FIB, the samples were further coated with $100 \mathrm{~nm}$ of electron-beam deposited Pt and $1 \mu \mathrm{m}$ of ion-beam deposited Pt to protect the area of interest during milling. Energy-dispersive x-ray spectroscopy was taken on the Titan in TEM mode with an energy range of $40 \mathrm{keV}$. To characterize the surface of the films, atomic force microscopy was conducted using a Cypher ES microscope from Asylum Research. The microscope was operated in peak-force tapping mode. Raman spectroscopy (Horiba) was used to verify film uniformity and characterize layer number for the $\mathrm{MoTe}_{2}$ films. The laser used was $633 \mathrm{~nm}$, with a laser power of $10 \%$ and diffraction grating $1800 \mathrm{~g} / \mathrm{mm}$. Full conversion of the films from $\mathrm{MoO}_{\mathrm{x}}$ to $\mathrm{MoTe}_{2}$ was verified through x-ray photoelectron spectroscopy (XPS) (PHI VersaProbe II).

\section{Chemical Vapor Transport Synthesis of Bulk Crystal MoTe 2 :}

Bulk crystal $2 \mathrm{H} \mathrm{MoTe} \mathrm{M}_{2}$ was synthesized in accordance with previously documented methods for the chemical vapor transport (CVT) mediated growth of molybdenum ditelluride ${ }^{[18]}$. 
Molybdenum powder (Sigma Aldrich) was mixed in a stoichiometric ratio with tellurium powder $(0.5 \mathrm{~g} / 1.33 \mathrm{~g})$. That mixture was ground with $2.13 \mathrm{~g}$ of $\mathrm{NaCl}$ and sealed in a fused silica tube under vacuum in an Ar atmosphere. The tube was placed in a 2-inch quartz tube in a two-zone furnace (MTI OTF-1200X-II) and heated to $1100{ }^{\circ} \mathrm{C}$, and subsequently cooled to $900{ }^{\circ} \mathrm{C}$ at a rate of $0.5^{\circ} \mathrm{C} /$ hour. The sample was then cooled at a rate of $5{ }^{\circ} \mathrm{C} /$ minute until room temperature.

Device Fabrication and Measurement:

For as-grown films, $10 / 100 \mathrm{~nm} \mathrm{Cr} / \mathrm{Au}$ electrodes were thermally deposited on the films using a Kurt Lesker Nano38 thermal evaporator immediately after synthesis. Contact regions were defined using a parallel bar $\mathrm{Cu}$ TEM grid as a physical mask, resulting in contact width of $80 \mu \mathrm{m}$ and channel width of $40 \mu \mathrm{m}$. For etched films, $\mathrm{MoTe}_{2}$ films were etched with Ar gas using an Oxford 100 reactive ion etcher for 10 seconds at $50 \mathrm{~W}$. Immediately after etching, 10/100 nm $\mathrm{Cr} / \mathrm{Au}$ electrodes were deposited using a Denton e-beam evaporator, using the parallel bar $\mathrm{Cu}$ TEM grid as the mask. Fabricated devices were measured in both a 4-probe and 2-probe geometry using a Quantum Design Physical Property Measurement System.

\section{Acknowledgements}

D. H. was supported by the NASA graduate student fellowship \#80NSSC19K1131. The fabrication of devices was supported by DOE BES DE-SC0014476. N.C.S and B.D. acknowledge support from the National Science Foundation Grant No. 1605129. The following user facilities are acknowledged for instrument use, scientific and technical assistance: the Yale West Campus Materials Characterization Core (MCC), the Yale Institute for Nanoscience and Quantum Engineering (YINQE), and the Imaging Facility of Advanced Science Research Center at the Graduate Center of CUNY.

\section{Conflict of Interest}

The authors declare no conflicts of interest. 
Supporting Information Available: Low-energy ion spectroscopy data showing oxide coverage for $\mathrm{MoO}_{\mathrm{x}}$ films, dark-field TEM of individual $2 \mathrm{H} \mathrm{MoTe} 2$ grains, linear fits of ALD cycle number vs $\mathrm{MoTe}_{2}$ layer number, additional Raman and AFM data to show large-scale uniformity, TEM images of $1 \mathrm{~T}^{\prime} \mathrm{MoTe}_{2}$, Raman spectra showing Ar etching effects, Cross-section TEM comparing $\mathrm{MoTe}_{2}$ growth on $\mathrm{SiO}_{2}$ vs Sapphire, Raman and EDX for converted $\mathrm{WTe}_{2}$ thin film. This material is available free of charge via the Internet at http://pubs.acs.org. 


\section{References}

(1) Wang, Q. H.; Kalantar-Zadeh, K.; Kis, A.; Coleman, J. N.; Strano, M. S. Electronics and Optoelectronics of Two-Dimensional Transition Metal Dichalcogenides. Nat.

Nanotechnol. 2012, 7, 699-712.

(2) Chhowalla, M.; Jena, D.; Zhang, H. Two-Dimensional Semiconductors for Transistors. Nat. Rev. Mater. 2016, 1, 16052.

(3) Wang, J.; Ma, F.; Sun, M. Graphene, Hexagonal Boron Nitride, and Their Heterostructures: Properties and Applications. RSC Adv. 2017, 7, 16801-16822.

(4) Jariwala, D.; Sangwan, V. K.; Lauhon, L. J.; Marks, T. J.; Hersam, M. C. Emerging Device Applications for Semiconducting Two-Dimensional Transition Metal Dichalcogenides. ACS Nano 2014, 8, 1102-1120.

(5) Yang, H.; Kim, S. W.; Chhowalla, M.; Lee, Y. H. Structural and Quantum-State Phase Transition in van Der Waals Layered Materials. Nat. Phys. 2017, 13, 931-937.

(6) Pan, X. C.; Chen, X.; Liu, H.; Feng, Y.; Wei, Z.; Zhou, Y.; Chi, Z.; Pi, L.; Yen, F.; Song, F.; Wan, X.; Yang, Z.; Wang, B.; Wang, G.; Zhang, Y. Pressure-Driven Dome-Shaped Superconductivity and Electronic Structural Evolution in Tungsten Ditelluride. Nat. Commun. 2015, 6, 7805.

(7) Kang, D.; Zhou, Y.; Yi, W.; Yang, C.; Guo, J.; Shi, Y.; Zhang, S.; Wang, Z.; Zhang, C.; Jiang, S.; Li, A.; Yang, K.; Wu, Q.; Zhang, G.; Sun, L.; Zhao, Z. Superconductivity Emerging from a Suppressed Large Magnetoresistant State in Tungsten Ditelluride. Nat. Commun. 2015, 6, 7804.

(8) Qi, Y.; Naumov, P. G.; Ali, M. N.; Rajamathi, C. R.; Schnelle, W.; Barkalov, O.; Hanfland, M.; Wu, S.-C.; Shekhar, C.; Sun, Y.; Sü, V.; Schmidt, M.; Schwarz, U.; Pippel, 
E.; Werner, P.; Hillebrand, R.; Förster, T.; Kampert, E.; Parkin, S.; Cava, R. J.; Felser, C.;

Yan, B.; Medvedev, S. A. Superconductivity in Weyl Semimetal Candidate MoTe2. Nat.

Commun. 2016, 7, 11038.

(9) Wu, S.; Fatemi, V.; Gibson, Q. D.; Watanabe, K.; Taniguchi, T.; Cava, R. J.; Jarillo-

Herrero, P. Observation of the Quantum Spin Hall Effect up to 100 Kelvin in a Monolayer

Crystal. Science 2018, 359, 76-79.

(10) Qian, X.; Liu, J.; Fu, L.; Li, J. Quantum Spin Hall Effect in Two - Dimensional Transition Metal Dichalcogenides. Science 2014, 346, 1344-1347.

(11) Soluyanov, A. A.; Gresch, D.; Wang, Z.; Wu, Q.; Troyer, M.; Dai, X.; Bernevig, B. A. Type-II Weyl Semimetals. Nature 2015, 527, 495-498.

(12) Wang, Z.; Gresch, D.; Soluyanov, A. A.; Xie, W.; Kushwaha, S.; Dai, X.; Troyer, M.;

Cava, R. J.; Bernevig, B. A. MoTe 2 A Type-II Weyl Topological Metal. Phys. Rev. Lett. 2016, $117,056805$.

(13) Xu, X.; Chen, S.; Liu, S.; Cheng, X.; Xu, W.; Li, P.; Wan, Y.; Yang, S.; Gong, W.; Yuan, K.; Gao, P.; Ye, Y.; Dai, L. Millimeter-Scale Single-Crystalline Semiconducting $\mathrm{MoTe}_{2}$ via Solid-to-Solid Phase Transformation. J. Am. Chem. Soc. 2019, 141, 2128-2134.

(14) Hou, W.; Azizimanesh, A.; Sewaket, A.; Peña, T.; Watson, C.; Liu, M.; Askari, H.; Wu, S. M. Strain-Based Room-Temperature Non-Volatile $\mathrm{MoTe}_{2}$ Ferroelectric Phase Change Transistor. Nat. Nanotechnol. 2019, 14, 668-673.

(15) Wang, Y.; Xiao, J.; Zhu, H.; Li, Y.; Alsaid, Y.; Fong, K. Y.; Zhou, Y.; Wang, S.; Shi, W.; Wang, Y.; Zettl, A.; Reed, E. J.; Zhang, X. Structural Phase Transition in Monolayer $\mathrm{MoTe}_{2}$ Driven by Electrostatic Doping. Nature 2017, 550, 487-491.

(16) Zhang, C.; KC, S.; Nie, Y.; Liang, C.; Vandenberghe, W. G.; Longo, R. C.; Zheng, Y.; 
Kong, F.; Hong, S.; Wallace, R. M.; Cho, K. Charge Mediated Reversible Metal-Insulator Transition in Monolayer $\mathrm{MoTe}_{2}$ and $\mathrm{W}_{\mathrm{x}} \mathrm{Mo}_{1-\mathrm{x}} \mathrm{Te}_{2}$ Alloy. ACS Nano 2016, 10, 7370-7375.

(17) Keum, D. H.; Cho, S.; Kim, J. H.; Choe, D.-H.; Sung, H.-J.; Kan, M.; Kang, H.; Hwang, J.-Y.; Kim, S. W.; Yang, H.; Chang, K. J.; Lee, Y. H. Bandgap Opening in Few-Layered Monoclinic $\mathrm{MoTe}_{2}$. Nat. Phys. 2015, 11, 482-486.

(18) Martella, C.; Melloni, P.; Cinquanta, E.; Cianci, E.; Alia, M.; Longo, M.; Lamperti, A.; Vangelista, S.; Fanciulli, M.; Molle, A. Engineering the Growth of $\mathrm{MoS}_{2}$ via Atomic Layer Deposition of Molybdenum Oxide Film Precursor. Adv. Electron. Mater. 2016, 2, 1600330.

(19) Lin, W.-S.; Medina, H.; Su, T.-Y.; Lee, S.-H.; Chen, C.-W.; Chen, Y.-Z.; Manikandan, A.; Shih, Y.-C.; Yang, J.-H.; Chen, J.-H.; Wu, B.-W.; Chu, K.-W.; Chuang, F.-C.; Shieh, J.M.; Shen, C.-H.; Chueh, Y.-L. Selection Role of Metal Oxides into Transition Metal Dichalcogenide Monolayers by a Direct Selenization Process. ACS Appl. Mater. Interfaces 2018, 10, 9645-9652.

(20) Medina, H.; Li, J.-G.; Su, T.-Y.; Lan, Y.-W.; Lee, S.-H.; Chen, C.-W.; Chen, Y.-Z.; Manikandan, A.; Tsai, S.-H.; Navabi, A.; Zhu, X.; Shih, Y.-C.; Lin, W.-S.; Yang, J.-H.; Thomas, S. R.; Wu, B.-W.; Shen, C.-H.; Shieh, J.-M.; Lin, H.-N.; Javey, A.; Wang, K. L.; Chueh, Y.-L. Wafer-Scale Growth of WSe 2 Monolayers Toward Phase-Engineered Hybrid $\mathrm{WO}_{x} / \mathrm{WSe}_{2}$ Films with Sub-Ppb $\mathrm{NO}_{x}$ Gas Sensing by a Low-Temperature Plasma-Assisted Selenization Process. Chem. Mater. 2017, 29, 1587-1598.

(21) Xu, X.; Wang, Z.; Lopatin, S.; Quevedo-Lopez, M. A.; Alshareef, H. N. Wafer Scale Quasi Single Crystalline $\mathrm{MoS}_{2}$ Realized by Epitaxial Phase Conversion. 2D Mater. 2019, 6, 015030. 
Zhou, J.; Liu, F.; Lin, J.; Huang, X.; Xia, J.; Zhang, B.; Zeng, Q.; Wang, H.; Zhu, C.; Niu, L.; Wang, X.; Fu, W.; Yu, P.; Chang, T. R.; Hsu, C. H.; Wu, D.; Jeng, H. T.; Huang, Y.; Lin, H.; Shen, Z.; Yang, C.; Lu, L.; Suenaga, K.; Zhou, W.; Pantelides, S. T.; Liu, G.; Liu, Z. Large-Area and High-Quality 2D Transition Metal Telluride. Adv. Mater. 2017, 29, 1603471.

(23) Zhou, J.; Lin, J.; Huang, X.; Zhou, Y.; Chen, Y.; Xia, J.; Wang, H.; Xie, Y.; Yu, H.; Lei, J.; Wu, D.; Liu, F.; Fu, Q.; Zeng, Q.; Hsu, C.-H.; Yang, C.; Lu, L.; Yu, T.; Shen, Z.; Lin, H.; Yakobson, B. I.; Liu, Q.; Suenaga, K.; Liu, G.; Liu, Z. A Library of Atomically Thin Metal Chalcogenides. Nature 2018, 556, 355-359.

He, Q.; Li, P.; Wu, Z.; Yuan, B.; Luo, Z.; Yang, W.; Liu, J.; Cao, G.; Zhang, W.; Shen, Y.; Zhang, P.; Liu, S.; Shao, G.; Yao, Z. Molecular Beam Epitaxy Scalable Growth of Wafer-Scale Continuous Semiconducting Monolayer $\mathrm{MoTe}_{2}$ on Inert Amorphous Dielectrics. Adv. Mater. 2019, 31, 1901578.

(25) Empante, T. A.; Zhou, Y.; Klee, V.; Nguyen, A. E.; Lu, I. H.; Valentin, M. D.; Naghibi Alvillar, S. A.; Preciado, E.; Berges, A. J.; Merida, C. S.; Gomez, M.; Bobek, S.; Isarraraz, M.; Reed, E. J.; Bartels, L. Chemical Vapor Deposition Growth of Few-Layer $\mathrm{MoTe}_{2}$ in the 2H, 1T', and 1T Phases: Tunable Properties of $\mathrm{MoTe}_{2}$ Films. ACS Nano 2017, 11, 900-905.

(26) Cheol Park, J.; Joon Yun, S.; Kim, H.; Park, J.-H.; Hoon Chae, S.; An, S.-J.; Kim, J.-G.; Min Kim, S.; Kang Kim, K.; Hee Lee, Y. Phase-Engineered Synthesis of CentimeterScale 1T' and 2H-Molybdenum Ditelluride Thin Films. ACS Nano 2015, 9, 6548-6554.

(27) Huang, J.-H.; Deng, K.-Y.; Liu, P.-S.; Wu, C.-T.; Chou, C.-T.; Chang, W.-H.; Lee, Y.-J.; Hou, T.-H. Large-Area 2D Layered MoTe 2 by Physical Vapor Deposition and Solid-Phase 
Crystallization in a Tellurium-Free Atmosphere. Adv. Mater. Interfaces 2017, 4, 1700157.

(28) Huang, J.-H.; Hsu, H.-H.; Wang, D.; Lin, W.-T.; Cheng, C.-C.; Lee, Y.-J.; Hou, T.-H. Polymorphism Control of Layered $\mathrm{MoTe}_{2}$ through Two-Dimensional Solid-Phase Crystallization. Sci. Rep. 2019, 9, 8810.

(29) Giri, A.; Yang, H.; Jang, W.; Kwak, J.; Thiyagarajan, K.; Pal, M.; Lee, D.; Singh, R.; Kim, C.; Cho, K.; Soon, A.; Jeong, U. Synthesis of Atomically Thin Transition Metal Ditelluride Films by Rapid Chemical Transformation in Solution Phase. Chem. Mater. 2018, 30, 2463-2473.

(30) Zhou, L.; Xu, K.; Zubair, A.; Liao, A. D.; Fang, W.; Ouyang, F.; Lee, Y. H.; Ueno, K.; Saito, R.; Palacios, T.; Kong, J.; Dresselhaus, M. S. Large-Area Synthesis of High-Quality Uniform Few-Layer MoTe2. J. Am. Chem. Soc. 2015, 137, 11892-11895.

(31) Woods, J. M.; Hynek, D.; Liu, P.; Li, M.; Cha, J. J. Synthesis of WTe 2 Nanowires with Increased Electron Scattering. ACS Nano 2019, 13, 6455-6460.

(32) Zhou, Y.; Jang, H.; Woods, J. M.; Xie, Y.; Kumaravadivel, P.; Pan, G. A.; Liu, J.; Liu, Y.; Cahill, D. G.; Cha, J. J. Direct Synthesis of Large-Scale WTe 2 Thin Films with Low Thermal Conductivity. Adv. Funct. Mater. 2017, 27, 1605928.

(33) Ruppert, C.; Aslan, O. B.; Heinz, T. F. Optical Properties and Band Gap of Single- and Few-Layer MoTe 2 Crystals. Nano Lett. 2014, 14, 6231-6236.

(34) Song, Q. J.; Tan, Q. H.; Zhang, X.; Wu, J. B.; Sheng, B. W.; Wan, Y.; Wang, X. Q.; Dai, L.; Tan, P. H. Physical Origin of Davydov Splitting and Resonant Raman Spectroscopy of Davydov Components in Multilayer MoTe2. Phys. Rev. B 2016, 93, 115409.

Grzeszczyk, M.; Gołasa, K.; Zinkiewicz, M.; Nogajewski, K.; Molas, M. R.; Potemski, M.; Wysmołek, A.; Babiñski, A. Raman Scattering of Few-Layers MoTe2. 2D Mater. 
2016, 3, 025010.

(36) Lezama, I. G.; Arora, A.; Ubaldini, A.; Barreteau, C.; Giannini, E.; Potemski, M.;

Morpurgo, A. F. Indirect-to-Direct Band Gap Crossover in Few-Layer MoTe2. Nano Lett.

$\mathbf{2 0 1 5}, 15,2336-2342$.

(37) Cho, S.; Kim, S.; Kim, J. H.; Zhao, J.; Seok, J.; Keum, D. H.; Baik, J.; Choe, D. H.;

Chang, K. J.; Suenaga, K.; Kim, S. W.; Lee, Y. H.; Yang, H. Phase Patterning for Ohmic Homojunction Contact in MoTe2. Science 2015, 349, 625-628.

(38) Li, H.; Li, Y.; Aljarb, A.; Shi, Y.; Li, L. J. Epitaxial Growth of Two-Dimensional Layered Transition-Metal Dichalcogenides: Growth Mechanism, Controllability, and Scalability.

Chem. Rev. 2018, 118, 6134-6150.

(39) Shang, S. L.; Lindwall, G.; Wang, Y.; Redwing, J. M.; Anderson, T.; Liu, Z. K. Lateral Versus Vertical Growth of Two-Dimensional Layered Transition-Metal Dichalcogenides: Thermodynamic Insight into $\mathrm{MoS}_{2}$. Nano Lett. 2016, 16, 5742-5750.

(40) Zhang, X.; Choudhury, T. H.; Chubarov, M.; Xiang, Y.; Jariwala, B.; Zhang, F.; Alem, N.; Wang, G.-C.; Robinson, J. A.; Redwing, J. M. Diffusion-Controlled Epitaxy of Large Area Coalesced $\mathrm{WSe}_{2}$ Monolayers on Sapphire. Nano Lett. 2018, 18, 1049-1056.

(41) Kozhakhmetov, A.; Choudhury, T. H.; Al Balushi, Z. Y.; Chubarov, M.; Redwing, J. M. Effect of Substrate on the Growth and Properties of Thin 3R $\mathrm{NbS}_{2}$ Films Grown by Chemical Vapor Deposition. J. Cryst. Growth 2018, 486, 137-141.

(42) Groven, B.; Nalin Mehta, A.; Bender, H.; Meersschaut, J.; Nuytten, T.; Verdonck, P.; Conard, T.; Smets, Q.; Schram, T.; Schoenaers, B.; Stesmans, A.; Afanas'Ev, V.; Vandervorst, W.; Heyns, M.; Caymax, M.; Radu, I.; Delabie, A. Two-Dimensional Crystal Grain Size Tuning in $\mathrm{WS}_{2}$ Atomic Layer Deposition: An Insight in the Nucleation 
Mechanism. Chem. Mater. 2018, 30, 7648-7663.

(43) Xu, W.; Yan, J.; Wu, N.; Zhang, H.; Xie, Y.; Tang, Y.; Zhu, Y.; Yao, W. Diffusing Behavior of $\mathrm{MoO}_{3}$ on $\mathrm{Al}_{2} \mathrm{O}_{3}$ and $\mathrm{SiO}_{2}$ Thin Films. Surf. Sci. 2000, 470, 121-130.

(44) Zhang, D.; Wang, Y.; Gan, Y. Characterization of Critically Cleaned Sapphire SingleCrystal Substrates by Atomic Force Microscopy, XPS and Contact Angle Measurements. Appl. Surf. Sci. 2013, 274, 405-417.

(45) Bertuch, A.; Sundaram, G.; Saly, M.; Moser, D.; Kanjolia, R. Atomic Layer Deposition of Molybdenum Oxide Using Bis(Tert-Butylimido)Bis(Dimethylamido) Molybdenum. $J$. Vac. Sci. Technol. A Vacuum, Surfaces, Film. 2014, 32, 01 A119. 